\title{
Regulation of ERG3, ERG6, and ERG11 Genes in Antifungal-Resistant isolates of Candida parapsilosis
}

\author{
Ensieh Lotfali ${ }^{1}$, Ali Ghajari ${ }^{1}$, Parivash Kordbacheh ${ }^{2}$, Farideh Zaini ${ }^{2}$, Hossein Mirhendi ${ }^{3}$, \\ Rasoul Mohammadi ${ }^{3}$, Fatemeh Noorbakhsh ${ }^{4}$ and Sassan Rezaie ${ }^{* 5}$
}

\begin{abstract}
${ }^{1}$ Department of Medical Parasitology and Mycology, School of Medicine, Shahid Beheshti University of Medical Sciences, Tehran, Iran; ${ }^{2}$ Department of Medical Parasitology and Mycology, School of Public Health, Tehran University of Medical Sciences, Tehran, Iran; ${ }^{3}$ Department of Medical Parasitology and Mycology, School of Medicine, Infectious Disease and Tropical Medicine Research Center, Isfahan University of Medical Sciences, Isfahan, Iran; ${ }^{4}$ Department of Biology, Faculty of Science, Islamic Azad University, Varamin-Pishva, Iran; ${ }^{5}$ Division of Molecular Biology, Department of Medical Mycology and Parasitology, School of Public Health, Tehran University of Medical Sciences, Tehran, Iran
\end{abstract}

Received 28 May 2016; revised 18 June 2016; accepted 2 July 2016

\begin{abstract}
Background: Candida parapsilosis is one of the five common strains of yeasts involved in invasive candidiasis. The expression analysis of sterol biosynthesis pathway genes, which are associated with resistance, can assist the better understanding of antifungal resistance mechanisms. Methods: The antifungal susceptibility of 120 clinical C. parapsilosis isolates was examined. The changes in the gene expression related to resistance were analyzed. Results: Eight strains were resistant to fluconazole (FLC), itraconazole (ITC), and amphotericin B (AMB). The regulation variations included increased mRNA levels of ERG3, ERG6, and ERG11 and decreased mRNA levels of ERG3 and ERG6 in response to FLC. ERG11 mRNA level increases in response to ITC and AMB. Conclusion: The mechanism of resistance to azoles in C. parapsilosis is very similar to $C$. Albicans. This feature may help to design new treatment strategy for candidiasis. DOI: 10.18869/acadpub.ibj.21.4.275
\end{abstract}

Keywords: Candida parapsilosis, Gene expression, Ergosterol biosynthesis

Corresponding Author: Sassan Rezaie

Division of Molecular Biology, Department of Medical Mycology and Parasitology, school of public health, Tehran university of medical sciences,

Tehran, Iran; E-mail: srezaie@tums.ac.ir

\section{INTRODUCTION}

$\mathrm{T}$ he rate of candidiasis among patients has increased largely in recent years. One of the five frequent yeast strains involved in invasive candidiasis is Candida parapsilosis that is mainly common in neonates and in catheter-associated candidemia $^{[1]}$.

Lanosterol 14-demethylase is a member of cytochrome P450 enzyme family that is required for the synthesis of ergosterol. This enzyme is encoded by the ERG11 gene, and it is a target for azoles. Azoles, especially fluconazole (FLC), are the most common drugs used for the treatment of candidiasis ${ }^{[2]}$.

Long-term treatment of candidiasis and the emergence of resistance to azole and polyene drugs usually result in treatment failure ${ }^{[3]}$. However, the pathway for fungal sterol biosynthesis is still a known and confirmed target for antifungal drug development. In ergosterol biosynthesis pathway, there are other genes, i.e. ERG3 and ERG6, that have not yet been characterized completely.

The 14-methyl fecosterol accumulation is caused by mutations in the ERG3 gene. C. albicans erg 3 mutants are able to resist both polyene and azole treatment ${ }^{[4]}$. Sterol content analysis of erg3 mutants shows an accumulation of sterol intermediates, i.e. 14-methyl fecosterol, which led to an impairment in the final steps of the ergosterol pathway ${ }^{[5]}$.

Sequencing of ERG6 gene has indicated a specific missense mutation in ERG6 where cysteine is replaced with phenylalanine ${ }^{[5]}$. 
Resistance to polyenes is less common than azoles, but it has been recently reported in Candida species ${ }^{[6,7]}$.

In the present study, eight resistant strains of $C$. parapsilosis were isolated from clinical samples. Their resistance to specific antifungal agents was validated by in vitro susceptibility assay. Using real-time PCR method, we made an attempt to investigate the possible alterations in expression profile of some ergosterol biosynthetic genes such as ERG3, ERG6, and ERG11 in resistant species ${ }^{[8]}$.

\section{MATERIALS AND METHODS}

\section{Clinical isolates}

In total, 120 clinical C. parapsilosis isolates, obtained from a collection of clinical isolates, were recovered during an epidemiological study in three provinces of Iran (Tehran, Mazandaran, and Isfahan), between June 2009 and June $2010^{[9]}$.

\section{Antifungal agents}

FLC (Tehran Daru, Iran), amphotericin B (AMB, Sigma-Aldrich, USA) and itraconazole (ITC, Tehran Daru, Iran) were selected as drugs to be used in susceptibility tests. The stock solutions of FLC were prepared in distilled water. However, for $\mathrm{AMB}$ and ITC, we used DMSO. The solutions were then kept frozen at $-70^{\circ} \mathrm{C}$ until use. Dilution of antifungal drugs was performed with RPMI 1640 medium (Invitrogen, USA) and buffered to $\mathrm{pH} 7.0$ with $0.165 \mathrm{M}$ morpholine propane sulfonic acid buffer as described previously $(\text { Sigma, USA })^{[10]}$.

\section{Antifungal susceptibility testing}

Reference antifungal susceptibility testing of the isolates was performed by the broth microdilution method described in Clinical and Laboratory Standards Institute (CLSI) guidelines, document $\mathrm{M} 27-\mathrm{S} 3^{[11]}$. $C$. parapsilosis ATCC 22019 type strain from the American type culture collection was used as a control for antifungal susceptibility testing ${ }^{[11]}$. According to the guidelines of CLSI, concentration ranges were $0.125-64 \mu \mathrm{g} / \mathrm{ml}$ for FLC and $0.03-16 \mu \mathrm{g} / \mathrm{ml}$ for AMB and ITC $^{[11]}$. The assay was carried out in 96-well round-bottom microtiter plates. Cell suspensions were prepared in RPMI 1640 medium and were adjusted to give a final inoculum concentration of about $0.5 \times 10^{3}$ $2.5 \times 10^{3}$ cells $/ \mathrm{ml}$. The plates were then incubated at $35^{\circ} \mathrm{C}$ and read after $48 \mathrm{~h}^{[12]}$. The minimum inhibitory concentrations (MICs) were then determined from the readings and compared with a drug-free control. All tests were performed in duplicate. The MIC results were read according to the M27-S3 supplement of the CLSI Guide.

\section{RNA purification}

Total RNA was extracted from $C$. parapsilosis cells using a commercial kit (Fermentas, EU). Yeast cells were harvested at the exponential phase of growth. $C$. parapsilosis culture was grown in sabouraud media (without antifungal drugs) at $32^{\circ} \mathrm{C}$ for $48 \mathrm{~h}$ and grown to an optical density of approximately 0.5-1.0 at 600 nm. Total RNA was extracted according to the manufacturer's instruction.

\section{RT-PCR}

\section{First-strand cDNA synthesis}

First-strand cDNA was synthesized from $0.1 \mathrm{ng}$ to 5 $\mu \mathrm{g}$ of total RNA in a $20 \mu \mathrm{l}$ reaction volume using a commercial kit (Fermentas, EU) according to the manufacturer's instructions. Primers were designed using the Oligo Explorer (version 15) software and were listed in Table 1. The obtained PCR fragment was estimated to be 150-200 bp.

\section{Real-time PCR}

Real-time PCR was performed in a Step One Plus real-time PCR system (Applied Biosystems, Foster City, CA), and SYBR Premix Ex Taq II was used as a reagent specifically designed for intercalator-based real-time PCR. PCR reaction mixtures contained $2 \mu \mathrm{l}$ of first strand cDNA, $10 \mu \mathrm{l} \mathrm{SYBR}$ green, $0.8 \mu \mathrm{l}$ of each

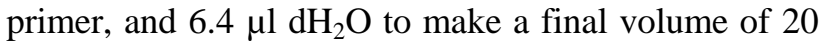
$\mu \mathrm{L}$. PCR was performed on a Rotor-Gene 3000 system (Corbett Life Sciences, Sydney, Australia) with a preliminary hold at $94^{\circ} \mathrm{C}$ for $30 \mathrm{~s}$ as initial denaturation step, followed by the 45 cycles PCR step consisting of $95^{\circ} \mathrm{C}$ for $50 \mathrm{~s}, 58^{\circ} \mathrm{C}$ for $20 \mathrm{~s}$ and $72^{\circ} \mathrm{C}$ for $30 \mathrm{~s}$. Final holding was performed at $72^{\circ} \mathrm{C}$ for $1 \mathrm{~min}$, and melting step was performed at $65-99^{\circ} \mathrm{C}$.

To quantify the possible changes in ERG3, ERG6, and ERG11 genes expression levels in C. Parapsilosis, RT PCR was performed. ERG3, ERG6, ERG11 genes expression were normalized to the housekeeping gene, ACT1, and analyzed by using RESTC software (2008, v. 2.0.7). The software uses the comparative $\mathrm{Ct}$ method $(\Delta \Delta \mathrm{Ct})$ to analyse the data. A sensitive strain (positive

Table 1. Primers used in quantitative real-time PCR analysis

\begin{tabular}{lll}
\hline Gene & Primer & Sequence \\
\hline \multirow{2}{*}{ ERG11 } & Forward & 5' CAG AAA AGT GGC GTT GTT GA 3' \\
& Reverse & 5' GCA GCA TCA CGT TTC CAA TA 3' \\
\multirow{2}{*}{ ERG3 } & Forward & 5' AGT GGG TGC AGT GAT ACA GT 3' \\
& Reverse & 5' TGC GGG TAA GAA GGT TGG TT 3' \\
& & \\
\multirow{2}{*}{$E R G 6$} & Forward & 5' AGC TAC CGT TCA TGC TCC AG 3' \\
& Reverse & 5' GTT CGG CAA CTT CAC GAC TG 3' \\
\hline
\end{tabular}


control) of $C$. parapsilosis was included in each run of the experiment as a positive control. Experiments under each condition were performed in duplicate, and each experiment was repeated twice on two different days to assess the reproducibility ${ }^{[13]}$.

\section{RESULTS}

\section{Determination of MIC}

Evaluation of the antifungal susceptibility tests showed that three $(2.5 \%)$ isolates of $C$. Parapsilosis strains were resistant to FLC $\left(\mathrm{FLC}_{\mathrm{R} 1}, \mathrm{FLC}_{\mathrm{R} 2}, \mathrm{FLC}_{\mathrm{R} 3}\right.$ : $\mathrm{MIC} \geq 8 \mu \mathrm{g} / \mathrm{ml})$. In addition, three $(2.5 \%)$ and two $(1.66 \%)$ isolates indicated resistance to ITC $\left(\right.$ ITC $_{R 1}$, $\left.\mathrm{ITC}_{\mathrm{R} 2}, \quad \mathrm{ITC}_{\mathrm{R} 3}: \mathrm{MIC} \geq 1 \mu \mathrm{g} / \mathrm{ml}\right)$ and AMB $\left(\mathrm{AMB}_{\mathrm{R} 1}\right.$,
$\left.\mathrm{AMB}_{\mathrm{R} 2}: \mathrm{MIC} \geq 1 \mu \mathrm{g} / \mathrm{ml}\right)$, respectively. There was no cross-resistance to drugs between the eight strains.

\section{Expression analysis of ERG3, ERG6, and ERG11 genes using $\Delta \mathbf{\Delta} \mathbf{C t}$ method}

ERG3, ERG6, ERG11, and ACT1 (housekeeping gene) mRNA levels were examined in all resistant strains $\left(\mathrm{FLC}_{\mathrm{R} 1}, \mathrm{FLC}_{\mathrm{R} 2}, \mathrm{FLC}_{\mathrm{R} 3}, \mathrm{ITR}_{\mathrm{R} 1}, \mathrm{ITR}_{\mathrm{R} 2}, \mathrm{ITR}_{\mathrm{R} 3}\right.$, $\mathrm{AMB}_{\mathrm{R} 1}$, and $\mathrm{AMB}_{\mathrm{R} 2}$ ). The output of RESTC software (2008, v. 2.0.7) was calculated for indication of ERG3, ERG6, and ERG11 gene expression in the treated cells after the normalization of their expression to the housekeeping gene in all strains. Table 2 shows the results of data analysis using RESTC) software (2008, v. 2.0.7). Figure 1 indicates the relative gene expression level of ERG3, ERG6, and ERG11.

Table 2. Results for relative expression of ERG3, ERG6, and ERG11 genes by use of $\Delta \Delta \mathrm{Ct}$ method (REST@), 2008, v. 2.0.7)

\begin{tabular}{|c|c|c|c|c|c|c|}
\hline & Gene & Resistance strain & Type & Expression & $\mathbf{P}($ H1) & Result \\
\hline \multirow{9}{*}{ 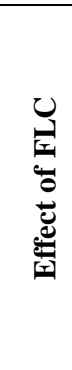 } & \multirow{3}{*}{ ERG3 } & $\mathrm{FLC}_{\mathrm{R} 1}$ & TRG & 3.986 & 0.000 & Up \\
\hline & & $\mathrm{FLC}_{\mathrm{R} 2}$ & TRG & 20.393 & 0.000 & Up \\
\hline & & $\mathrm{FLC}_{\mathrm{R} 3}$ & TRG & 3.031 & 0.175 & - \\
\hline & \multirow{3}{*}{ ERG6 } & $\mathrm{FLC}_{\mathrm{R} 1}$ & TRG & 2.056 & 0.000 & Up \\
\hline & & $\mathrm{FLC}_{\mathrm{R} 2}$ & TRG & 1.803 & 0.000 & Up \\
\hline & & $\mathrm{FLC}_{\mathrm{R} 3}$ & TRG & 1.847 & 0.166 & - \\
\hline & \multirow{3}{*}{ ERG11 } & $\mathrm{FLC}_{\mathrm{R} 1}$ & TRG & 1.729 & 0.170 & - \\
\hline & & $\mathrm{FLC}_{\mathrm{R} 2}$ & TRG & 1.028 & 0.837 & - \\
\hline & & $\mathrm{FLC}_{\mathrm{R} 3}$ & TRG & 12.951 & 0.000 & Up \\
\hline \multirow{9}{*}{ 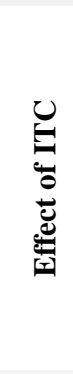 } & \multirow{3}{*}{ ERG3 } & $\mathrm{ITC}_{\mathrm{R} 1}$ & TRG & 0.503 & 0.339 & - \\
\hline & & $\mathrm{ITC}_{\mathrm{R} 2}$ & TRG & 0.796 & 0.000 & Down \\
\hline & & $\mathrm{ITC}_{\mathrm{R} 3}$ & TRG & 1.072 & 1.000 & - \\
\hline & \multirow{3}{*}{ ERG6 } & $\mathrm{ITC}_{\mathrm{R} 1}$ & TRG & 0.108 & 0.000 & Down \\
\hline & & $\mathrm{ITC}_{\mathrm{R} 2}$ & TRG & 0.109 & 0.182 & - \\
\hline & & $\mathrm{ITC}_{\mathrm{R} 3}$ & TRG & 0.184 & 0.000 & Down \\
\hline & \multirow{3}{*}{ ERG11 } & $\mathrm{ITC}_{\mathrm{R} 1}$ & TRG & 3.864 & 0.000 & Up \\
\hline & & $\mathrm{ITC}_{\mathrm{R} 2}$ & TRG & 15.945 & 0.000 & Up \\
\hline & & $\mathrm{ITC}_{\mathrm{R} 3}$ & TRG & 1.905 & 0.000 & Up \\
\hline \multirow{6}{*}{ 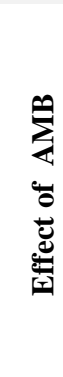 } & \multirow{2}{*}{ ERG3 } & $\mathrm{AMB}_{\mathrm{R} 1}$ & TRG & 0.064 & 0.000 & Down \\
\hline & & $\mathrm{AMB}_{\mathrm{R} 2}$ & TRG & 0.015 & 0.000 & Down \\
\hline & \multirow{2}{*}{ ERG6 } & \multirow{2}{*}{$\begin{array}{l}\mathrm{AMB}_{\mathrm{R} 1} \\
\mathrm{AMB}_{\mathrm{R} 2}\end{array}$} & TRG & 0.142 & 0.000 & Down \\
\hline & & & TRG & 0.135 & 0.000 & Down \\
\hline & \multirow[b]{2}{*}{ ERG11 } & $\mathrm{AMB}_{\mathrm{R} 1}$ & TRG & 1.270 & 0.328 & - \\
\hline & & $\mathrm{AMB}_{\mathrm{R} 2}$ & TRG & 2.071 & 0.000 & Up \\
\hline \multirow{2}{*}{\multicolumn{2}{|c|}{$\begin{array}{l}\text { Beta Act } \\
\text { Positive. control }\end{array}$}} & REF & REF & - & - & REF \\
\hline & & & & - & - & 1.000 \\
\hline
\end{tabular}

Up-regulation (UP) and down-regulation (Down) for $E R G$ genes. REF, reference gene; TRG, target gene;

FLC, fluconazole; ITC, itraconazole; AMB, amphotericin B 
FLC
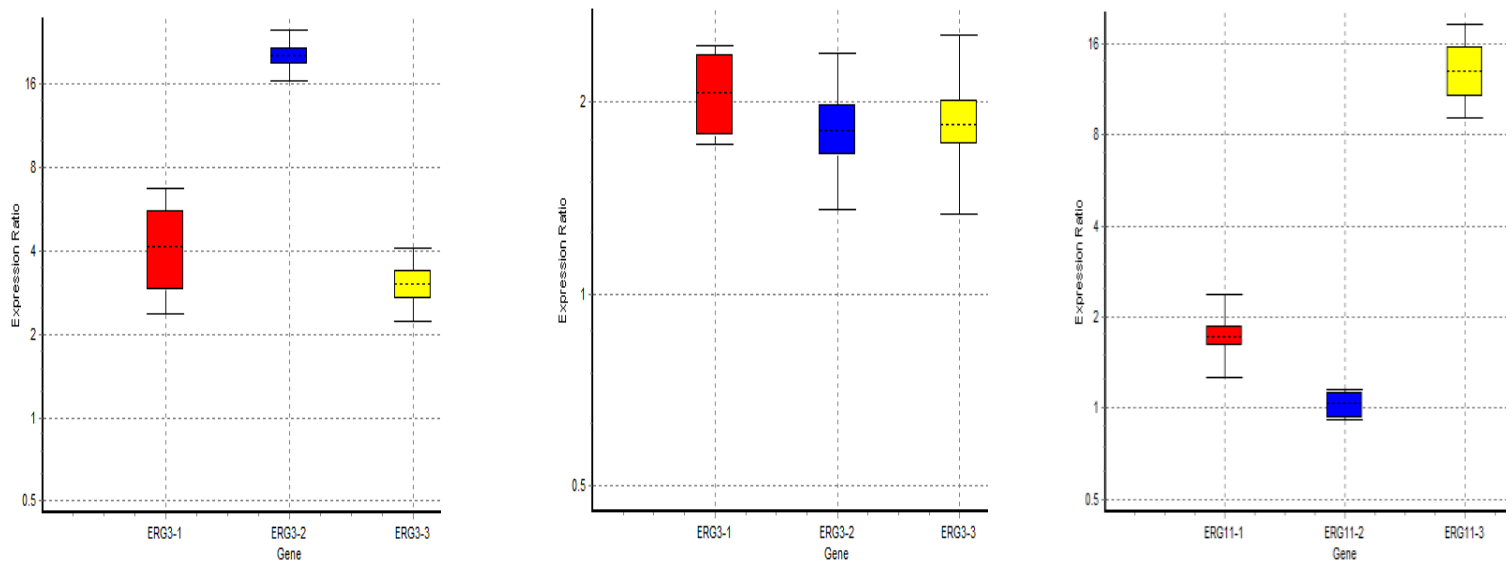

ITC
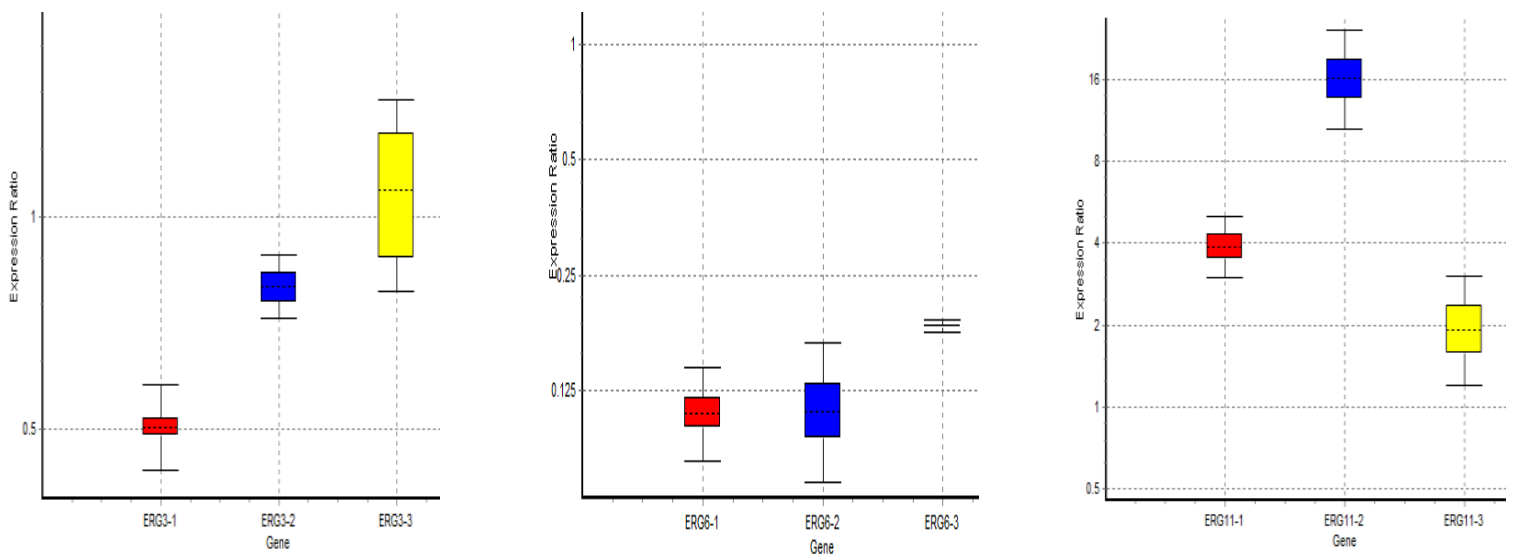

AMB

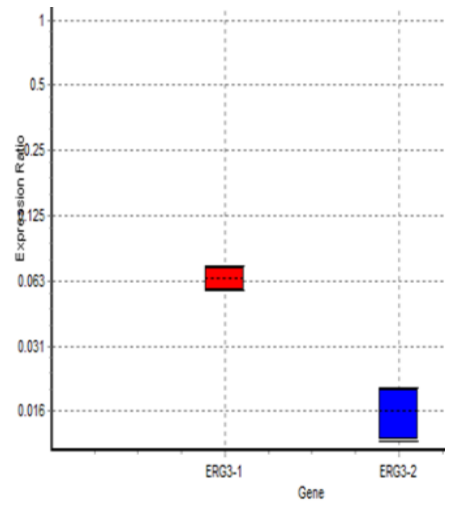

ERG3

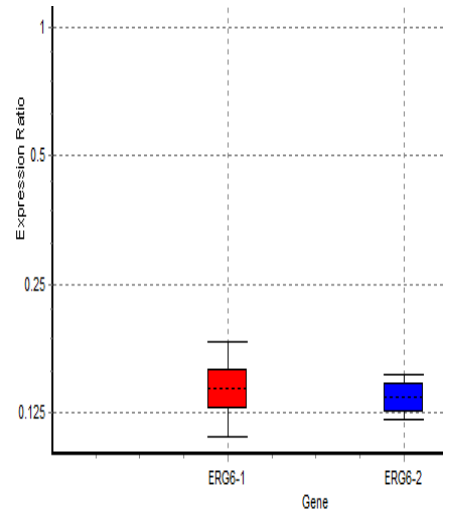

ERG6

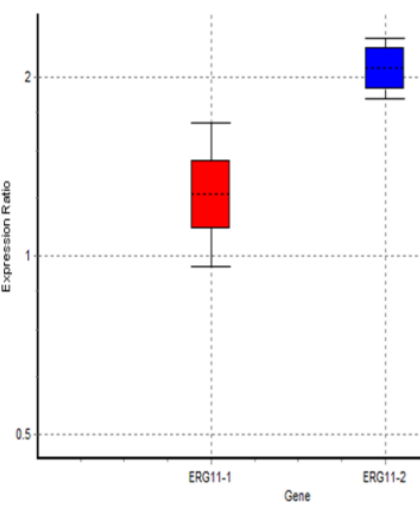

ERG11

Fig. 1. Effect of fluconazole (FLC), itraconazole (ITC), and amphotericin B (AMB) on ERG3, ERG6, and ERG11 genes expression. Colors represent resistant isolates (Red, no. 1; blue, no. 2; yellow, no. 3). Results of relative expression of ERG3, ERG6, and ERG11 genes was calculated using $\Delta \Delta \mathrm{Ct}$ method (RESTC), 2008, v2.0.7. Boxes represent the interquartile range, or the middle $50 \%$ of observations. The dotted lines signify the median gene expression. 


\section{DISCUSSION}

Infections due to $C$. parapsilosis have been reported in European and Asian countries and Latin America ${ }^{[10]}$. Azoles, especially FLC, are the most widely used drugs for the treatment of candidiasis. However, due to the high use of azole antifungals, the incidence of resistant strains of Candida has been increased ${ }^{[14-18]}$. $C$. parapsilosis is not prone to development of antifungal resistance, but recent reports indicated its increased resistance to azoles ${ }^{[10,19-21]}$. In the present study, we tried to look into the possible changes in the expression profile of ERG3, ERG6, and ERG11 genes in response to FLC, ITC, and AMB within eight resistance isolates of $C$. parapsilosis. In three isolates that showed resistance to ITC, we found a significant decrease in ERG3 mRNA level in $\mathrm{ITC}_{\mathrm{R} 2}$. However, mRNA levels of ERG6 were decreased in $\mathrm{ITC}_{\mathrm{R} 1}$ and $\mathrm{ITC}_{\mathrm{R} 3}$ isolates. Surprisingly, ERG11 mRNA levels increased in all mentioned isolates, i.e., $\mathrm{ITC}_{\mathrm{R} 1}, \mathrm{ITC}_{\mathrm{R} 2}$, and $\mathrm{ITC}_{\mathrm{R} 3}$.

Further analysis showed different expressions involved in the development of resistance to FLC among three isolates: increased mRNA levels of ERG3 (in $\mathrm{FLC}_{\mathrm{R} 1}$ and $\mathrm{FLCR}_{2}$ ), of ERG6 (in $\mathrm{FLC}_{\mathrm{R} 1}$ and $\mathrm{FLC}_{\mathrm{R} 2}$ ), and of ERG11 (only in $\mathrm{FLC}_{\mathrm{R} 3}$ ). Morio ${ }^{[22]}$ indicated genetic alterations in ERG3 that may have resulted from f FLC therapy. Berkow et al. ${ }^{[23]}$ found mutations in the sequence of the sterol biosynthesis genes (ERG3 and ERG11). Based on their findings, azole resistance contributes to $M D R I$ and $C D R I$ (putative drug transporters). Their findings also demonstrated that among azole-resistant isolates, $Y 132 F$ substitution in ERG11 is the only substitution. Also, mutation in ERG3 allows the fungal cell to produce toxic intermediate sterols and to become resistant to azoles and $\mathrm{AMB}^{[23]}$. Other investigations have shown that experimental increase in ERG11 level can cause increased azole resistance ${ }^{[24,25]}$. In addition, drug resistance to antifungals may be regulated by transcription factors ${ }^{[26]}$.

Resistance to the polyenes is rare but could be acquired by the loss-of-function mutations in ERG3, which can inhibit the formation of the drug-lipid complex, prevent osmotic cellular lysis and finally block the production of ergosterol. Mutations in ERG6 led to the accumulation of last sterol intermediates and reduced susceptibility to the polyenes in $C$. glabrata $^{[5,27]}$.

Based on our results, $\mathrm{AMB}_{\mathrm{R} 1}$ and $\mathrm{AMB}_{\mathrm{R} 2}$ isolates showed a decrease in mRNA level of ERG3 and ERG6, but $\mathrm{AMB}_{\mathrm{R} 2}$ isolate revealed an increase in ERG11 mRNA level. Therefore, we can conclude that the regulation of ERG3 and ERG6 and ERG11 genes could be different in the investigated isolates.
Lees et al. ${ }^{[28]}$ found that ERG11 (lanosterol demethylase) is essential for aerobic growth but is suppressed by mutations in the ERG3 gene, which is in accordance with our obtained results. Silva et al. ${ }^{[14]}$ reported that $C$. parapsilosis, like $C$. albicans, acquires resistance to azoles either through increased expression of the sterol biosynthetic pathway genes or via the upregulation of the $M D R 1$ multidrug transporter family. In Silva's study ${ }^{[14]}$, the expression of ERG3 and ERG11 was reduced in $\mathrm{FLC}_{\mathrm{R}}$ (-4.86 and -2.69 fold), whereas in our study, the expression of ERG3, ERG6, and ERG11 was increased or remained unchanged in $\mathrm{FLC}_{\mathrm{RS}}$ (from +1.028 to +20.39 ). Morio et al. ${ }^{[22]}$ suggested more extensive investigations on other genes, such as ERG3 and ERG6, which are involved in the ergosterol biosynthesis pathway, when azole resistance is suspected. Vandeputte et al. ${ }^{[7]}$ showed that a nonsense mutation detected in the ERG6 gene led to a decrease in ergosterol content in $C$. glabrata isolates. Expression of ERG11 and ERG3 genes was decreased upon exposure to AMB. Liu et al. ${ }^{[8]}$ observed that ketoconazole increases the expression of genes involved in sterol metabolism, lipids, and fatty acid, including ERG3 and ERG11. Similar to those findings, our results revealed that ERG3 and ERG6 genes were down-regulated due to exposure to AMB.

In summary, we can conclude that the mechanisms of resistance to azole drugs in $C$. parapsilosis and in $C$. albicans are the same. In addition, this finding may help in designing new strategies for antifungal therapy in Candida infections. However, further analysis is needed to determine the process by which mRNA levels for ERG3 and ERG6, as well as ERGII are altered in these isolates.

\section{ACKNOWLEDGMENTS}

This study was supported by the School of Public Health, Tehran University of Medical Sciences, Tehran (Iran) (Grant Number 26956).

CONFLICT OF INTEREST. None declared.

\section{REFERENCES}

1. Mirhendi H, Bruun B, Schoenheyder HC, Christensen JJ, Fuursted K, Gahrn-Hansen B, Johansen HK, Nielsen L, Knudsen JD, Arendrup MC. Molecular screening for Candida orthopsilosis and Candida metapsilosis among Danish Candida parapsilosis group blood culture isolates: proposal of a new RFLP profile for differentiation. Journal of medical microbiology 2010; 59(Pt 4): 414-420. 
2. Dunkel N, Liu TT, Barker KS, Homayouni R, Morschhäuser J, Rogers PD. A gain-of-function mutation in the transcription factor Upc2p causes upregulation of ergosterol biosynthesis genes and increased fluconazole resistance in a clinical Candida albicans isolate. Eukaryotic cell 2008 ;7(7): 1180-1190.

3. Morschhauser J. The genetic basis of fluconazole resistance development in Candida albicans. Biochim. Biochimica et biophysica acta 2002; 1587(2-3): 240248.

4. Martel CM, Parker JE, Bader O, Weig M, Gross U, Warrilow AG, Rolley N, Kelly DE, Kelly SL. Identification and characterization of four azoleresistant erg3 mutants of Candida albicans. Antimicrobial agents and chemotherapy 2010; 54(11): 4527-4533.

5. Vandeputte $P$, Tronchin $G$, Bergès $T$, Hennequin $C$, Chabasse D, Bouchara J-P. Reduced susceptibility to polyenes associated with a missense mutation in the ERG6 gene in a clinical isolate of Candida glabrata with pseudohyphal growth. Antimicrobial agents and chemotherapy 2007; 51(3): 982-990.

6. Rodero L, Mellado E, Rodriguez AC, Salve A, Guelfand L, Cahn P, Manuel Cuenca-Estrella, Graciela Davel, Juan L. Rodriguez-Tudela. G484S amino acid substitution in lanosterol $14-\alpha$ demethylase (ERG11) is related to fluconazole resistance in a recurrent Cryptococcus neoformans clinical isolate. Antimicrobial agents and chemotherapy 2003;47(11):3653-3656.

7. Vandeputte $P$, Tronchin G, Larcher G, Ernoult E, Bergès $\mathrm{T}$, Chabasse $\mathrm{D}$, Bouchara JP. A nonsense mutation in the ERG6 gene leads to reduced susceptibility to polyenes in a clinical isolate of Candida glabrata. Antimicrobial agents and chemotherapy 2008; 52(10): 3701-3709.

8. Liu TT, Lee RE, Barker KS, Lee RE, Wei L, Homayouni R, Rogers PD. Genome-wide expression profiling of the response to azole, polyene, echinocandin, and pyrimidine antifungal agents in Candida albicans. Antimicrobial agents and chemotherapy 2005; 49(6): 2226-2236.

9. Mohammadi R, Mirhendi H, Rezaei-Matehko-laei A, Ghahri M, Shidfar MR, Jalalizand N, Makimura K. Molecular identification and distribution profile of Candida species isolated from Iranian patients. Medical mycology 2013; 51(6): 657-663.

10. Silva AP, Miranda IM, Lisboa C, Pina-Vaz C, Rodrigues AG. Prevalence, distribution, and antifungal susceptibility profiles of Candida parapsilosis, $C$. orthopsilosis, and C. metapsilosis in a tertiary care hospital. Journal of clinical microbiology 2009; 47(8): 2392-2397.

11. CLSI. Implementation Guide of POCT for Health Care Providers; Approved Guideline. Wayne, PA: 2007.

12. CLSI. Reference Method for Broth Dilution Antifungal Susceptibility Testing of Yeasts; $4^{\text {th }}$ Informational Supplement. CLSI document M27-S4. Clinical and Laboratory Standards Institute, Wayne, PA: 2012.

13. Mohseni R, Noorbakhsh F, Moazeni M, Nasrollahi Omran A, Rezaie S. Antitoxin Characteristic of Licorice
Extract: The Inhibitory Effect on Aflatoxin Production in Aspergillus parasiticus. Journal of food safety 2014; 34(2): 119-125.

14. Silva A, Miranda I, Guida A, Synnott J, Rocha R, Silva $\mathrm{R}$, et al. Transcriptional profiling of azole-resistant Candida parapsilosis strains. Antimicrobial agents and chemotherapy 2011: 55(7) : 3546-3556.

15. Almirante B, Rodríguez D, Cuenca-Estrella M, Almela M, Sanchez F, Ayats J, Alonso-Tarres C, RodriguezTudela JL, Pahissa A. Epidemiology, risk factors, and prognosis of Candida parapsilosis bloodstream infections: case-control population-based surveillance study of patients in Barcelona, Spain, from 2002 to 2003. Journal of clinical microbiology 2006; 44(5): 1681-1615.

16. Medrano DJA, Brilhante RSN, Cordeiro RdA, Rocha MFG, Rabenhorst SHB, Sidrim JJC. Candidemia in a Brazilian hospital: the importance of Candida parapsilosis. Revista do instituto de medicina tropical de são paulo 2006;48(1):17-20.

17. Pfaller, MA, Diekema DJ. Epidemiology of invasive candidiasis: a persistent public health problem. Clinical Microbiology reviews 2007; 20(1): 133-163.

18. Tay ST, Na SL, Chong J. Molecular differentiation and antifungal susceptibilities of Candida parapsilosis isolated from patients with bloodstream infections. Journal of medical microbiology 2009; 58(2): 185-191.

19. Kuhn DM, Mukherjee PK, Clark TA, Pujol C, Chandra J, Hajjeh RA, Warnock DW, Soll DR, Ghannoum MA. Candida parapsilosis characterization in an outbreak setting. Emerging infectious diseases 2004; 10(6): 10741081.

20. Pfaller MA, Diekema DJ, Gibbs DL, Newell VA, Ng KP, Colombo A, Finquelievich J, Barnes R, Wadula J, Global Antifungal Surveillance Group. Geographic and temporal trends in isolation and antifungal susceptibility of Candida parapsilosis: a global assessment from the ARTEMIS DISK Antifungal Surveillance Program, 2001 to 2005. Journal of clinical microbiology 2008;46(3): 842-849.

21. van Asbeck E, Clemons KV, Martinez M, Tong A-J, Stevens DA. Significant differences in drug susceptibility among species in the Candida parapsilosis group. Diagnostic microbiology and infectious disease 2008; 62(1):106-9.

22. Morio F, Pagniez F, Lacroix C, Miegeville M, Le Pape P. Amino acid substitutions in the Candida albicans sterol $\Delta 5,6$-desaturase (Erg3p) confer azole resistance: characterization of two novel mutants with impaired virulence. Journal of antimicrobial chemotherapy 2012; 67(9): 2131-2138.

23. Berkow EL, Manigaba K, Parker JE, Barker KS, Kelly SL, Rogers PD. Multidrug transporters and alterations in sterol biosynthesis contribute to azole antifungal resistance in Candida parapsilosis. Antimicrobial agents and chemotherapy 2015; 59(10): 5942-5950.

24. Grossman NT, Pham CD, Cleveland AA, Lockhart SR. Molecular mechanisms of fluconazole resistance in Candida parapsilosis isolates from a US surveillance system. Antimicrobial agents and chemotherapy 2015; 
59(2): 1030-1037.

25. Du W, Coaker M, Sobel JD, Akins RA. Shuttle vectors for Candida albicans: control of plasmid copy number and elevated expression of cloned genes. Current genetics 2004; 45(6): 390-398.

26. Silver PM, Oliver BG, White TC. Role of Candida albicans transcription factor Upc2p in drug resistance and sterol metabolism. Eukaryotic Cell 2004; 3(6): 1391-1397.
27. Shapiro RS, Robbins N, Cowen LE. Regulatory circuitry governing fungal development, drug resistance, and disease. Microbiology and molecular biology reviews 2011; 75(2): 213-267.

28. Lees N, Skaggs B, Kirsch D, Bard M. Cloning of the late genes in the ergosterol biosynthetic pathway of Saccharomyces cerevisiae-a review. Lipids 1995; 30(3): 221-226. 